\title{
Glycopolycation-DNA Polyplex Formulation N/P Ratio Affects Stability, Hemocompatibility, and in Vivo Biodistribution
}

Haley R. Phillips,${ }^{\dagger}$ Zachary P. Tolstyka, ${ }^{\dagger}$ Bryan C. Hall,${ }^{\epsilon}$ Joseph K. Hexum,${ }^{\dagger}$ Perry B. Hackett ${ }^{\epsilon}$ Theresa M. Reineke ${ }^{\dagger, *}$

$\dagger$ University of Minnesota, Center for Genome Engineering and Department of Chemistry, 207 Pleasant Street SE, Minneapolis, MN 55455.

$€$ University of Minnesota, Center for Genome Engineering and Department of Genetics, Cell Biology, and Development, Minneapolis, MN 55455.

*To whom correspondence should be addressed: treineke@umn.edu

\section{SUPPORTING INFORMATION}

\section{Synthesis and Characterization of Polymers}

The MAG and MAEMt monomers and the P(MAG-b-MAEMt) polymers were synthesized and characterized previously (Scheme S1A, Figures S1-4). ${ }^{1-3}$ The P(MAG- $b$-MAEMt)-1, -2 , and -3 polymers were synthesized using RAFT polymerization for increasing periods of time to generate increasing MAEMt block lengths of 31, 42, and 76 repeat units. The polymers were dialyzed for 4 days in water (MWCO 3500) and characterized by ${ }^{1} \mathrm{H}$ NMR and size exclusion chromatography with static light scattering analysis (Scheme 1, main manuscript).

To prepare the new P(EG- $b$-MAEMt) control for this study, we first synthesized a PEG chain transfer agent (CTA) by coupling a $2000 \mathrm{Da}$ linear poly(ethylene glycol) methyl ether (mPEG, $4.12 \mathrm{~g}$, $2.05 \mathrm{mmol}, 1 \mathrm{eq}$ ) to a molecule of 4-cyano-4-(propylsulfanylthiocarbonyl) sulfanylpentanoic acid (CPP, $1.13 \mathrm{~g}, 4.07 \mathrm{mmol}, 2 \mathrm{eq}$ ) in the presence of 4-dimethylaminopyridine (DMAP, $263 \mathrm{mg}, 2.15$ mmol, 1 eq) and N,N'-dicyclohexylcarbodiimide (DIC, $505 \mathrm{mg}, 4.0 \mathrm{mmol}, 2 \mathrm{eq}$ ). The reaction was solvated by a mixture of $50 \mathrm{~mL}$ methylene chloride and $80 \mathrm{~mL}$ toluene and the reaction was run at 0 ${ }^{\circ} \mathrm{C}$ for $12 \mathrm{~h}$, then warmed to room temperature for another $20 \mathrm{~h}$ (Scheme S1B). A crystalline byproduct was filtered off and the golden yellow product was vacuum dried at $35^{\circ} \mathrm{C}$ overnight (yield: $2.21 \mathrm{~g}$, 
42.3\%). ${ }^{4}$ The PEG-CTA was characterized by ${ }^{1} \mathrm{H}$ NMR (see Figure S2). To chain extend from the PEG macroCTA, 1 eq CTA (764 mg, $34 \mathrm{mmol}$ ) was mixed with 0.1 eq 4,4'-azobis(4-cyanopentanoic acid) (V501, $\left.12.2 \mathrm{mg}, 44 \times 10^{-3} \mathrm{mmol}\right)$ and 56 eq MAEMt monomer $(2.00 \mathrm{~g}, 12 \mathrm{mmol})$ in $4: 1$ acetate buffer:ethanol at $70{ }^{\circ} \mathrm{C}$ for 14 hours under nitrogen atmosphere (Scheme S1B-C). The polymer was purified by dialysis $(3500 \mathrm{MWCO})$ in deionized water that was $\mathrm{pH}$ adjusted to 5-6 with $12.1 \mathrm{M} \mathrm{HCl}$ for 3 days, followed by lyophilization to dryness (yield: $0.9 \mathrm{~g}, 56 \%$ ). The light yellow, flakey product was characterized by ${ }^{1} \mathrm{H}$ NMR and SEC (see Figure S2).

Scheme S1. Synthesis of (A) MAEMt monomer and (B) PEG macroCTA. Polymerization of (C) P(EG-b-MAEMt) and (D) P(MAEMt).

A)

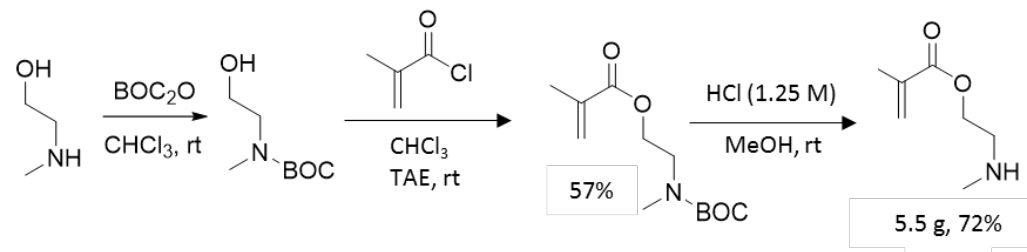

B)<smiles>CN(C)c1ccncc1</smiles>

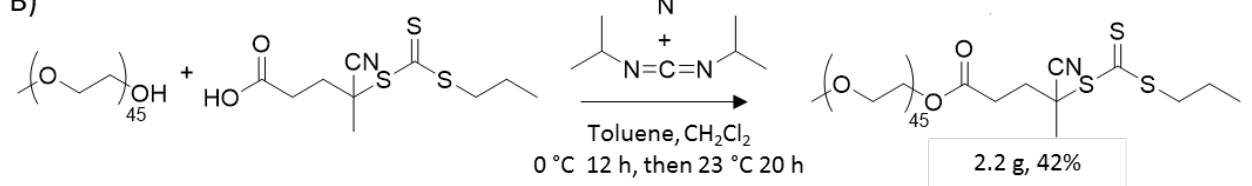
$n^{-}$ N

C)

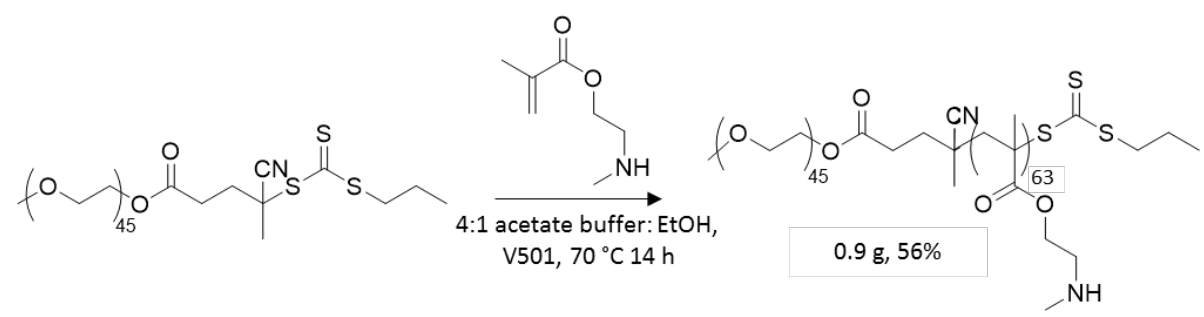

D)

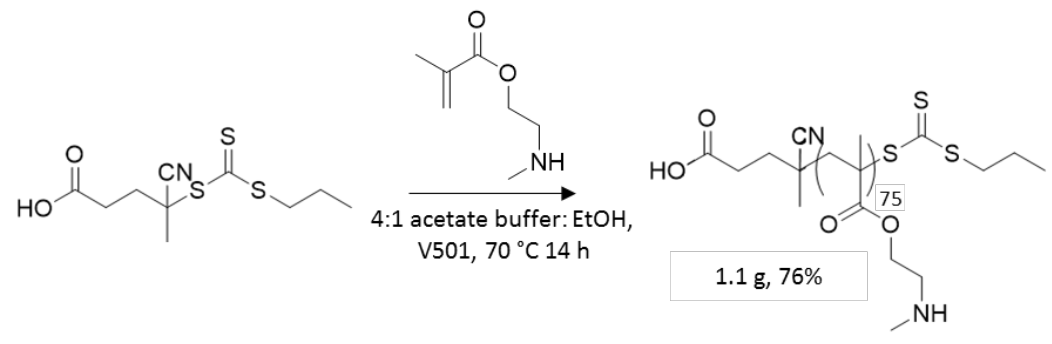


The same reaction conditions used to prepare $\mathrm{P}(\mathrm{EG}-b$-MAEMt) were employed to polymerize the homopolymer P(MAEMt) control, except that CPP was used in place of the PEG macroCTA (Scheme S1D). CPP (1 eq.; $\left.30.7 \mathrm{mg}, 111 \times 10^{-3} \mathrm{mmol}\right)$ plus 0.1 eq. V501 $\left(4.04 \mathrm{mg}, 14.4 \times 10^{-3} \mathrm{mmol}\right)$ and 56 eq. MAEMt monomer $(1.00 \mathrm{~g}, 6.24 \mathrm{mmol})$ were dissolved in 4:1 acetate buffer:ethanol and reacted at $70{ }^{\circ} \mathrm{C}$ for $14 \mathrm{~h}$ under nitrogen atmosphere. The polymer was dialyzed (300-500 MWCO) in deionized water adjusted to $\mathrm{pH}$ 5-6 with $\mathrm{HCl}$ for three days. After dialysis, the product was lyophilized to dryness and characterized by SEC and ${ }^{1} \mathrm{H}$ NMR (Figure S4).

\section{MAEMt Monomer Characterization}

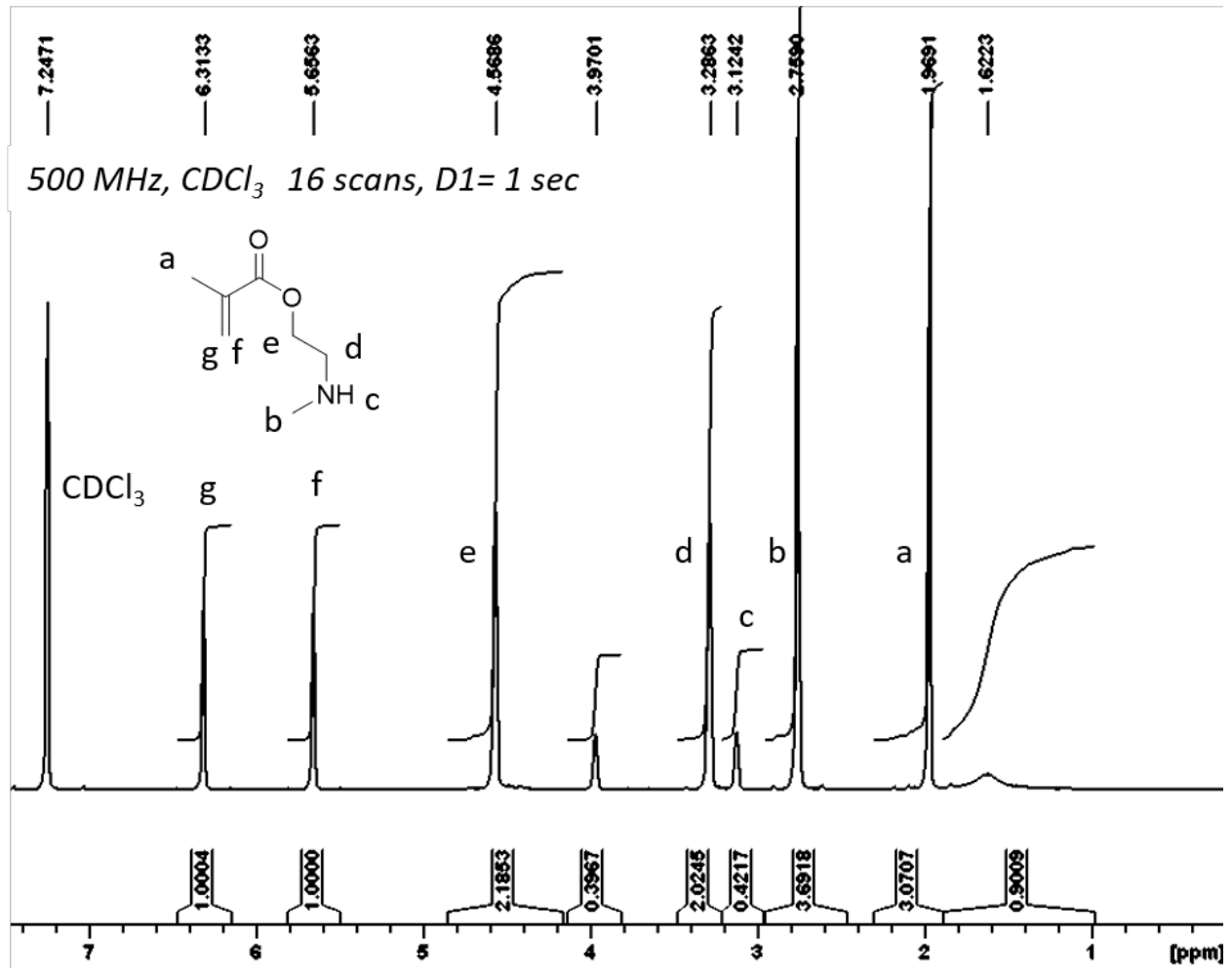

Figure S1. MAEMt monomer structure and ${ }^{1} \mathrm{H}$ NMR spectrum in $\mathrm{CDCl}_{3}$. 


\section{P(EG-b-MAEMt) Characterization}

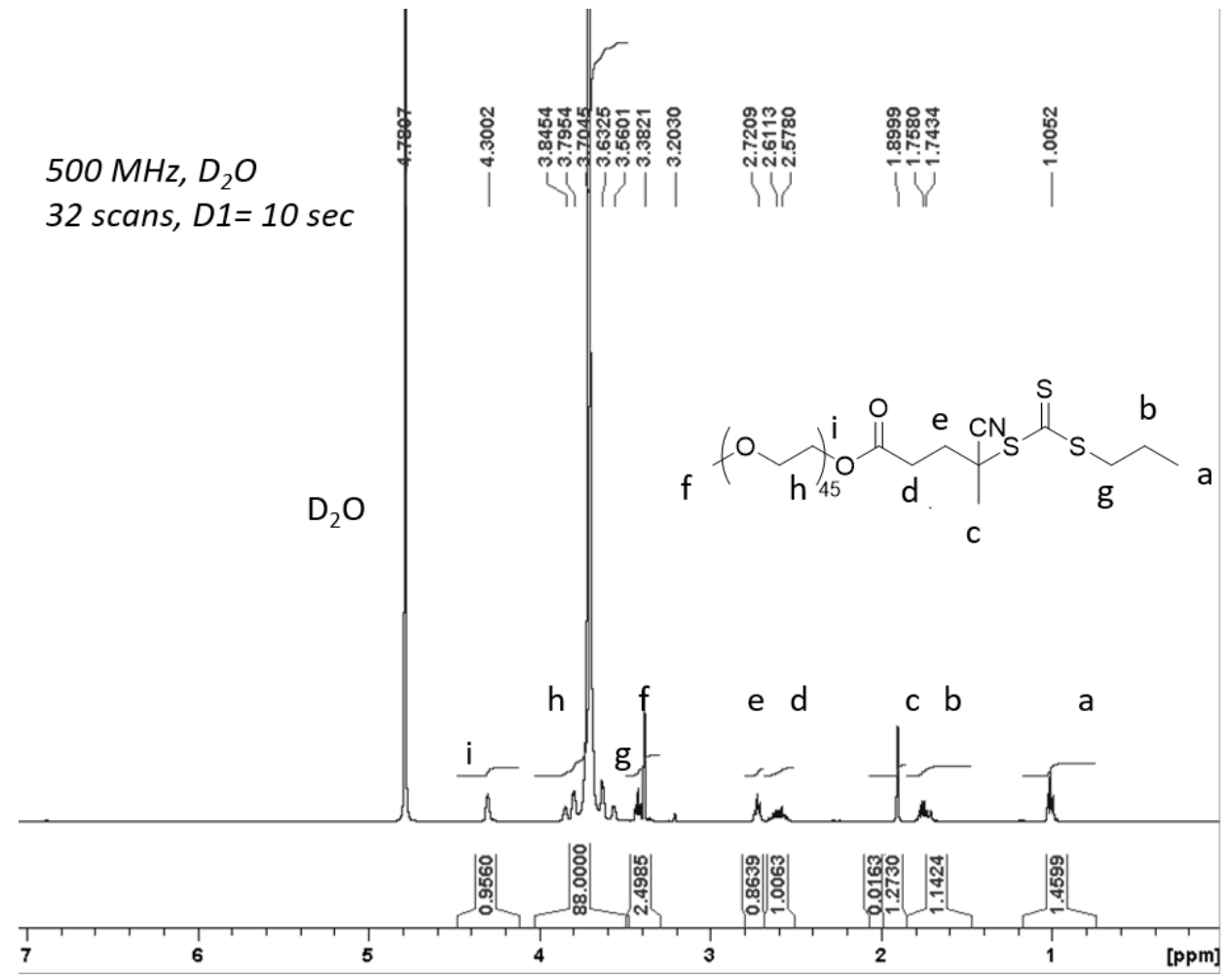

Figure S2. PEG macroCTA structure and ${ }^{1} \mathrm{H}$ NMR spectrum in $\mathrm{D}_{2} \mathrm{O}$.

P(EG- $b$-MAEMt) ${ }^{1} \mathrm{H}$ NMR $\left(\mathrm{D}_{2} \mathrm{O}\right)$ and SEC (eluent: $1.0 \mathrm{wt} \%$ acetic acid/0.1 $\left.\mathrm{M} \mathrm{Na}_{2} \mathrm{SO}_{4}\right)$. SEC flow rate was $0.4 \mathrm{~mL} / \mathrm{min}$, light scattering detector $(\lambda=662 \mathrm{~nm})$ and refractometer $(\lambda=658 \mathrm{~nm})$. 


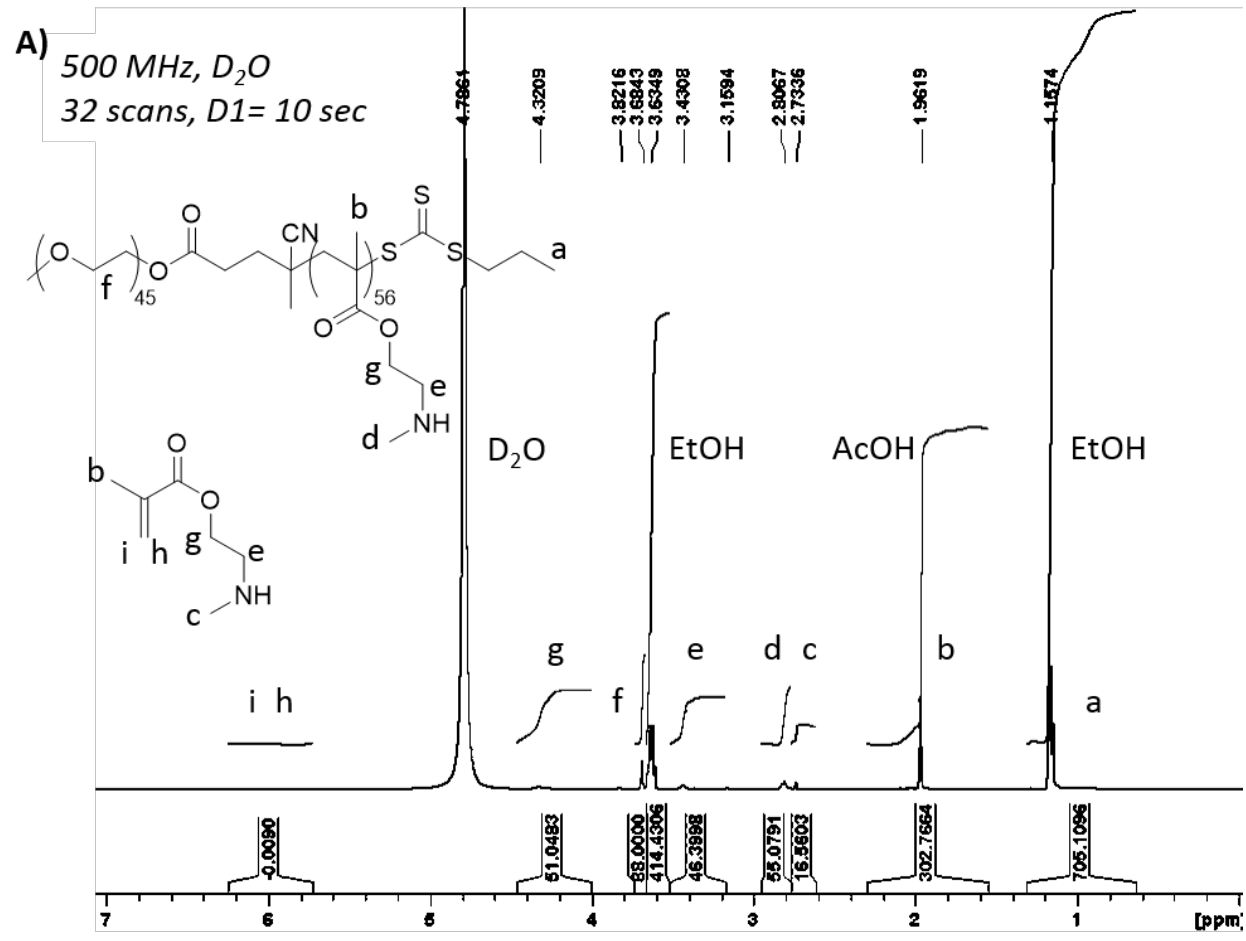

B)

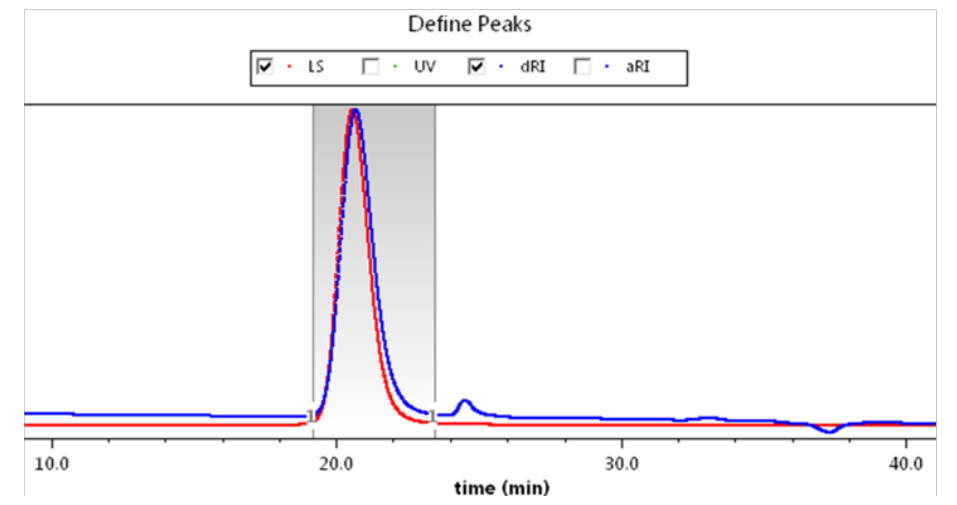

Figure S3. (A) ${ }^{1} \mathrm{H}$ NMR and (B) SEC traces (Red trace: light scattering; blue trace: refractive index) of $\mathrm{P}(\mathrm{EG}-b-\mathrm{MAEMt})$.

\section{P(MAEMt) Characterization}

P(MAEMt) ${ }^{1} \mathrm{H}$ NMR spectrum $\left(\mathrm{D}_{2} \mathrm{O}\right)$ and SEC trace (eluent: $1.0 \mathrm{wt} \%$ acetic acid/0.1 M $\left.\mathrm{Na}_{2} \mathrm{SO}_{4}\right)$. SEC flow rate was $0.4 \mathrm{~mL} / \mathrm{min}$, light scattering detector $(\lambda=662 \mathrm{~nm})$ and refractometer $(\lambda=$ $658 \mathrm{~nm})$. 


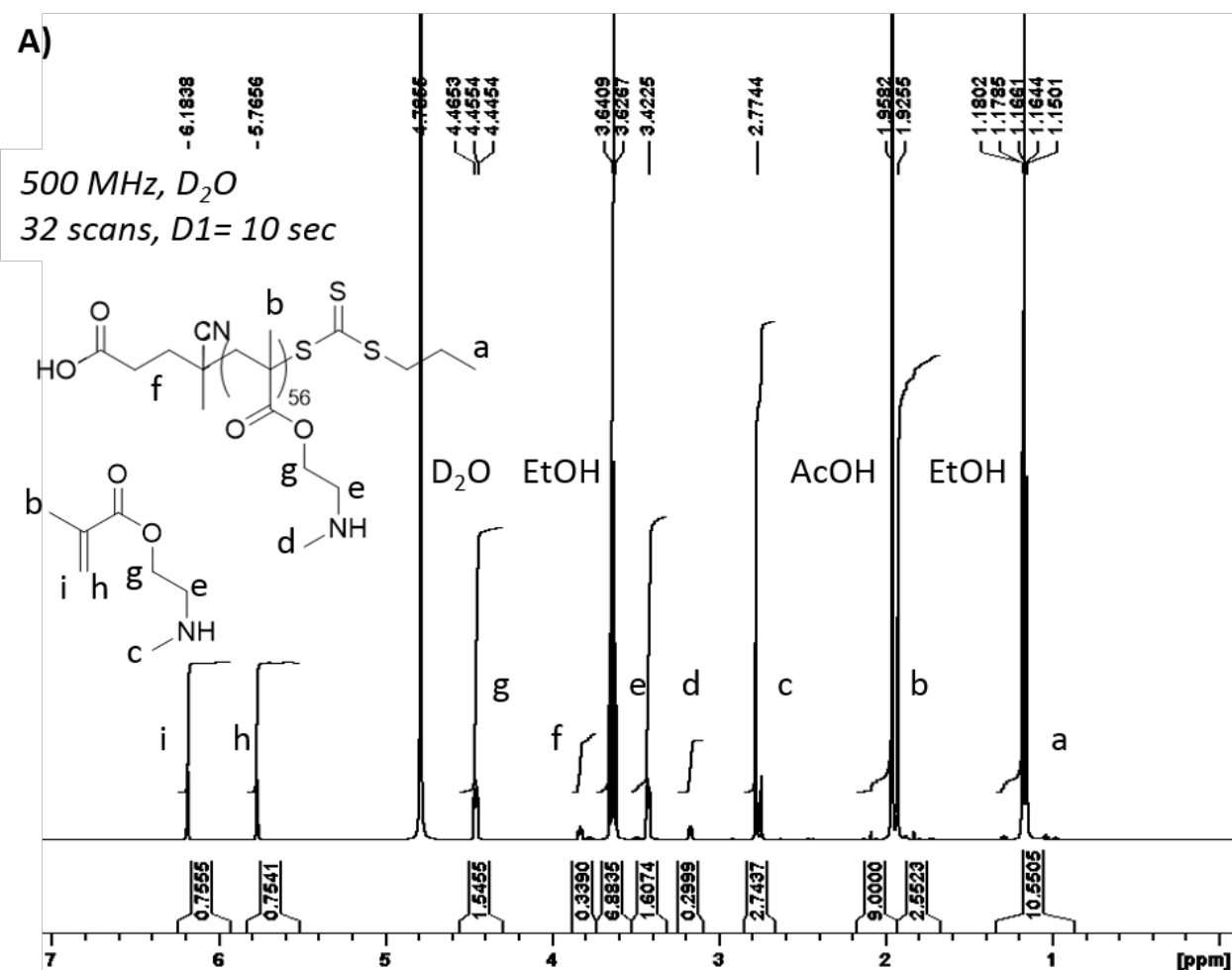

B)

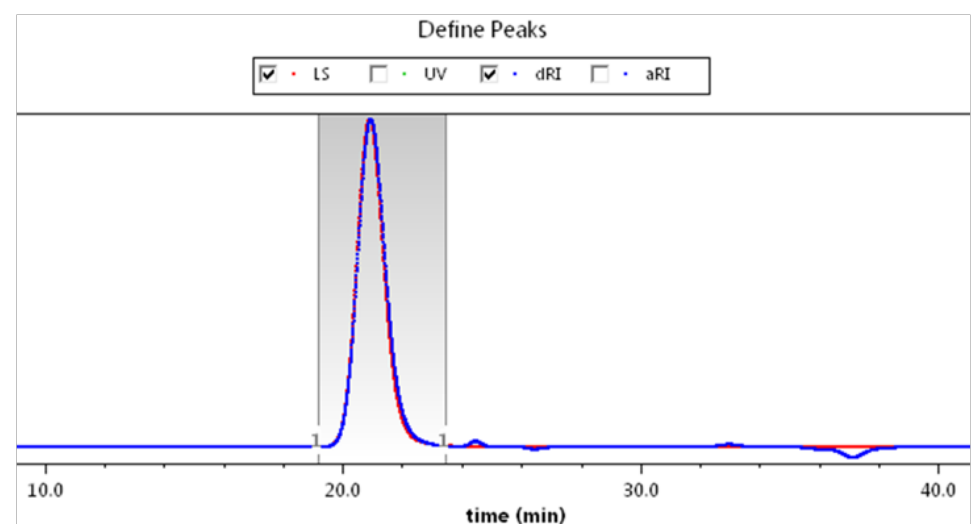

Figure S4. (A) ${ }^{1} \mathrm{H}$ NMR and (B) SEC traces (Red trace: light scattering; blue trace: refractive index) of $\mathrm{P}(\mathrm{MAEMt})$.

\section{Polymer Fluorescent Tagging Quantification}

To measure the degree of Cy7 tagging per polymer, the absorbance of P(MAG- $b$-MAEMt)-2Cy7 and $\mathrm{P}(\mathrm{EG}-b$-MAEMt)-Cy7 was measured in water $(0.2 \mathrm{mg} / \mathrm{mL})$ using UV-Vis (Figure S5A). To 
test whether polyplex formation quenched Cy7 fluorescence, fluorescence of free polymer and complexed polymer was compared using all in vivo formulations (Figure S5B).
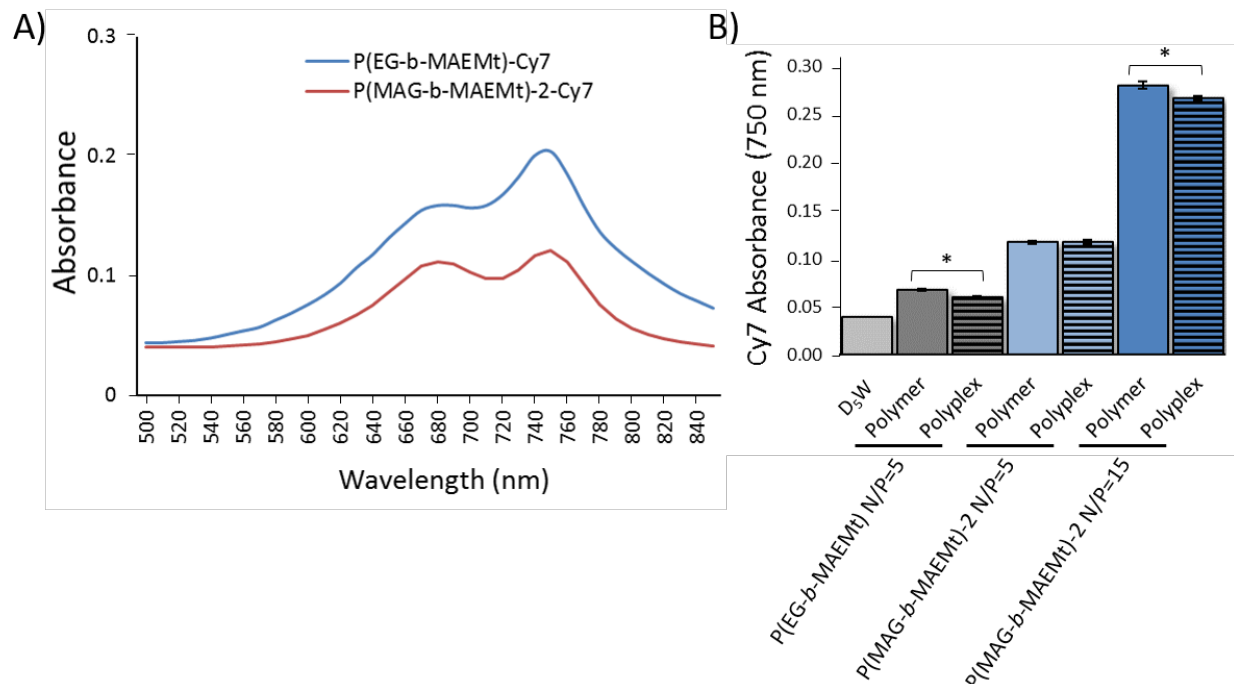

Figure S5. Cy7 fluorophore tagging characterization results. (A) Cy7 absorbance spectra for the two Cy7-labeled polymers in water. The degree of polymer tagging was determined using the peak absorbance at $\lambda=750 \mathrm{~nm}$. (B) Cy7-tagged sample absorbance comparing free Cy7-polymer to complexed Cy7-polymer. Each bar is the average of three samples with error bars denoting the standard deviation. (*) marks samples within the brackets that significantly differ from each other (Student's t-test $\mathrm{p}$ $<0.05)$.

\section{Polyplex Binding Study}

The ability of the polymers $\mathrm{P}(\mathrm{EG}-b-\mathrm{MAEMt})$, P(EG- $b$-MAEMt)-Cy7, and P(MAG- $b$ MAEMt)-Cy7 to complex DNA into polyplexes were analyzed by gel electrophoresis shift assays at $\mathrm{N} / \mathrm{P}=5$ and 15 . While the $\mathrm{P}(\mathrm{MAG}-b$-MAEMt)-1, -2 , and -3 polymers are to known to completely bind pDNA as low as $\mathrm{N} / \mathrm{P}=3,{ }^{53}$ it was necessary to test the binding capabilities of the new PEG control as well as the Cy7-labeled polymers used for in vivo studies. Commercial controls (jetPEI and Glycofect) as well as $\mathrm{P}(\mathrm{MAG}-b$-MAEMt)-2 at $\mathrm{N} / \mathrm{P}=5$ and 15 are used as controls. Complexed nucleic acids will not leave the well, but free plasmids migrate down the gel, as shown in the far-left column that contains the pT2/CAL pDNA only sample. The pDNA is not visible in the experimental polyplex standards as tight complexation can completely exclude EtBr from intercalating. ${ }^{5}$ 


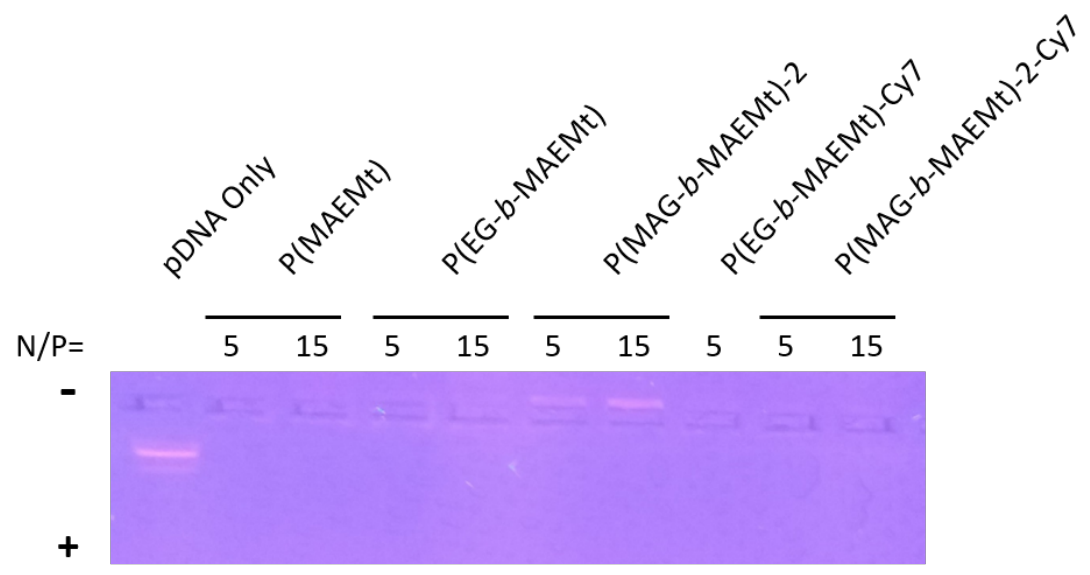

Figure S6. Gel electrophoresis of polyplex formulations with new polymers and with all polymers used in animal studies. All experimental polymers fully bound the plasmid DNA at $\mathrm{N} / \mathrm{P}=5$.

As an additional measure of polyplex stability, an EtBr exclusion study was performed (Figure S7). All polyplexes completely prevented EtBr from intercalating with the pDNA cargo.

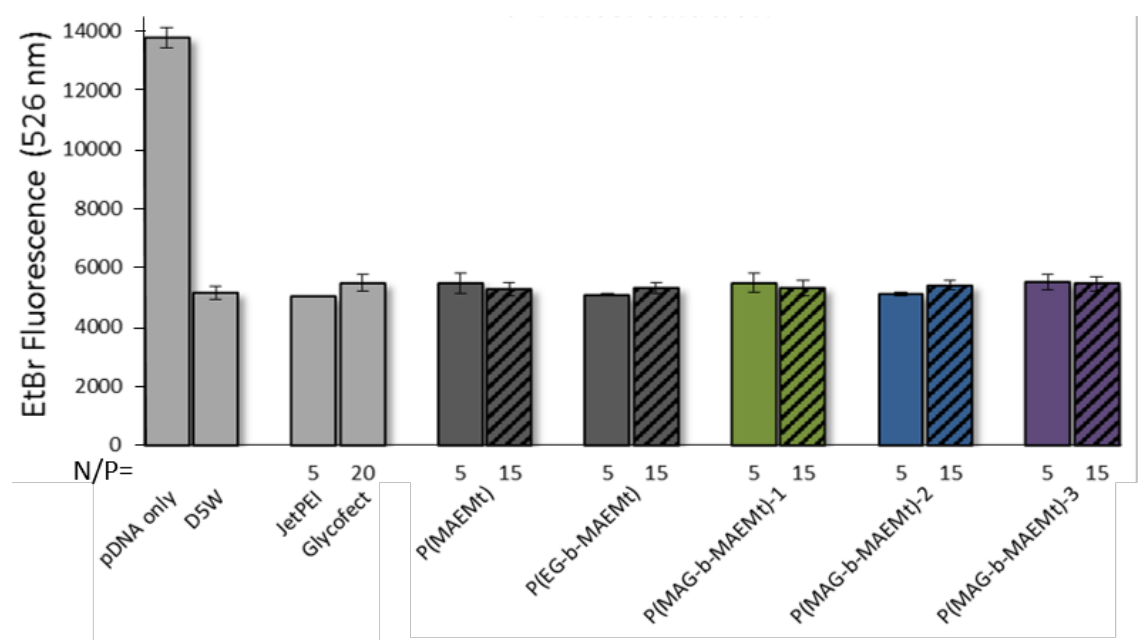

Figure S7. EtBr intercalation polyplex stability study. All polyplex samples prevented EtBr intercalation into pDNA cargo as compared to a pDNA only positive control. Each fluorescent sample was measured in triplicate (error bars represent the standard deviation) and samples that significantly differed from the $\mathrm{D}_{5} \mathrm{~W}$ negative control were marked with an asterisk (Student's ttest $\mathrm{p}<0.05)$.

\section{Size and Serum Stability Study}

For polyplex size stability dynamic light scattering (DLS) studies, polymer and pDNA solutions were filtered through a $0.22 \mu \mathrm{m}$ filter prior to mixing. Indicator-free DMEM containing FBS was 
filtered prior to polyplex dilution. The laser strength was set to $20 \mathrm{~mW}$. The first delay was set to $5 \mu \mathrm{s}$ and the last delay at $1 \times 10^{6} \mu \mathrm{s}$. The temperature was set at $23.3^{\circ} \mathrm{C}$. Data runs were $10 \mathrm{~min}$ for each sample, and the correlation functions were transformed by REPES analysis to the distribution curves seen below, plotted with Origin 2015 (Figures S8-20). The FBS only peak in Figure S8 was visually compared to subsequent DLS curves to rule out the FBS peak, and the diameter of the most dominant of the remaining peaks was plotted in Figure 1. While the cutoff point for each $\mathrm{x}$-axis differs, all peaks were plotted for each sample.

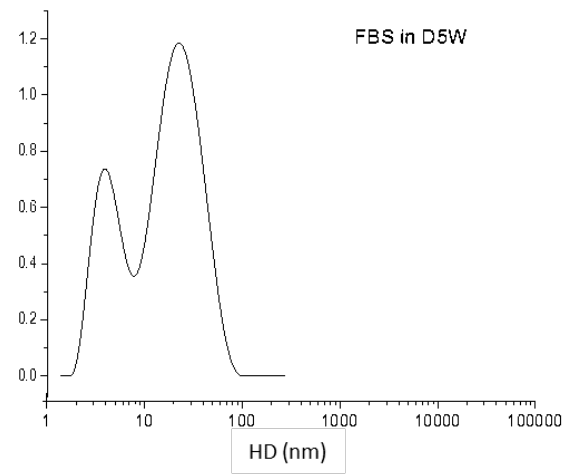

Figure S8. DLS correlation function of FBS only transformed by REPES analysis to present the data as a smoothed histogram. Timepoints taken after addition of FBS solution. The x-axis is the hydrodynamic diameter (HD) in nm, and the y-axis is unitless intensity. 

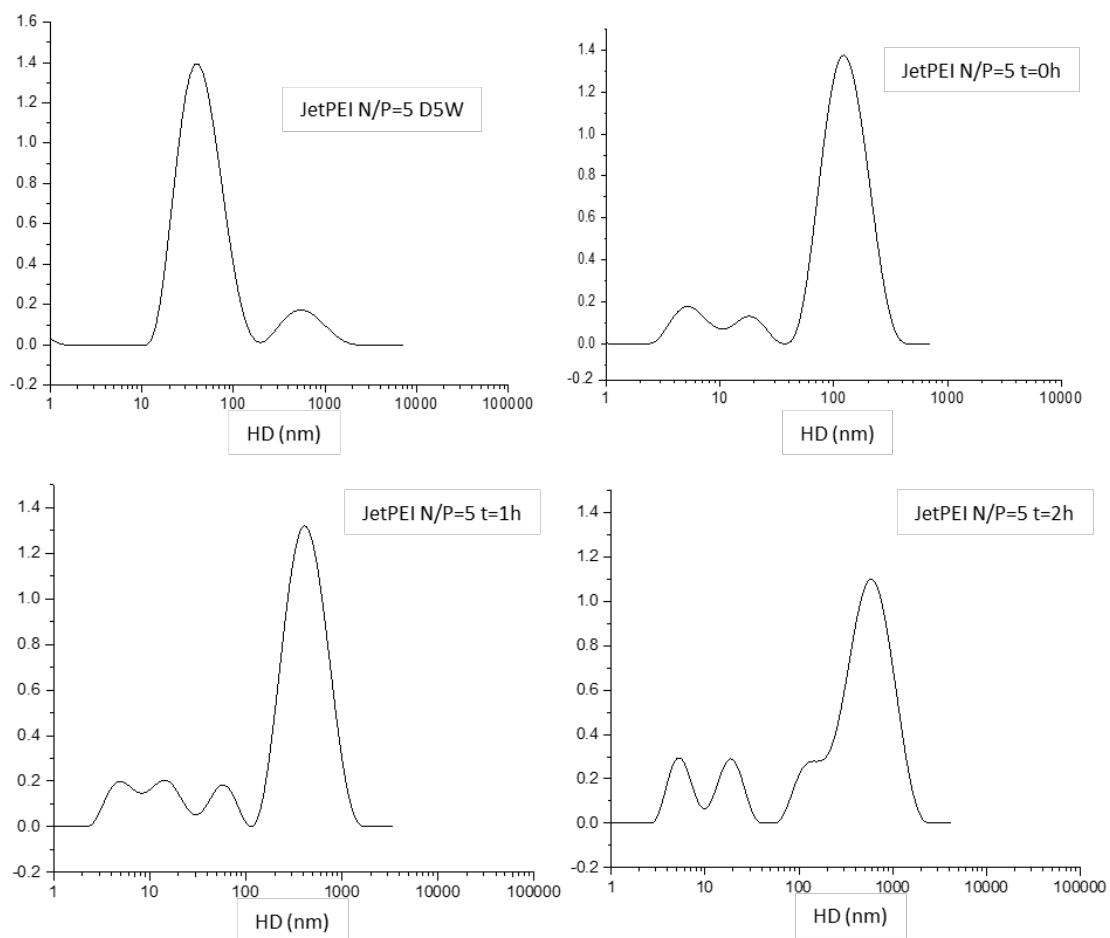

Figure S9. DLS correlation functions of jetPEI N/P $=5$ polyplexes over time transformed by REPES analysis to present the data as a smoothed histogram. Timepoints taken after addition of FBS solution. The $\mathrm{x}$-axis is the hydrodynamic diameter (HD) in $\mathrm{nm}$, and the y-axis is unitless intensity. 

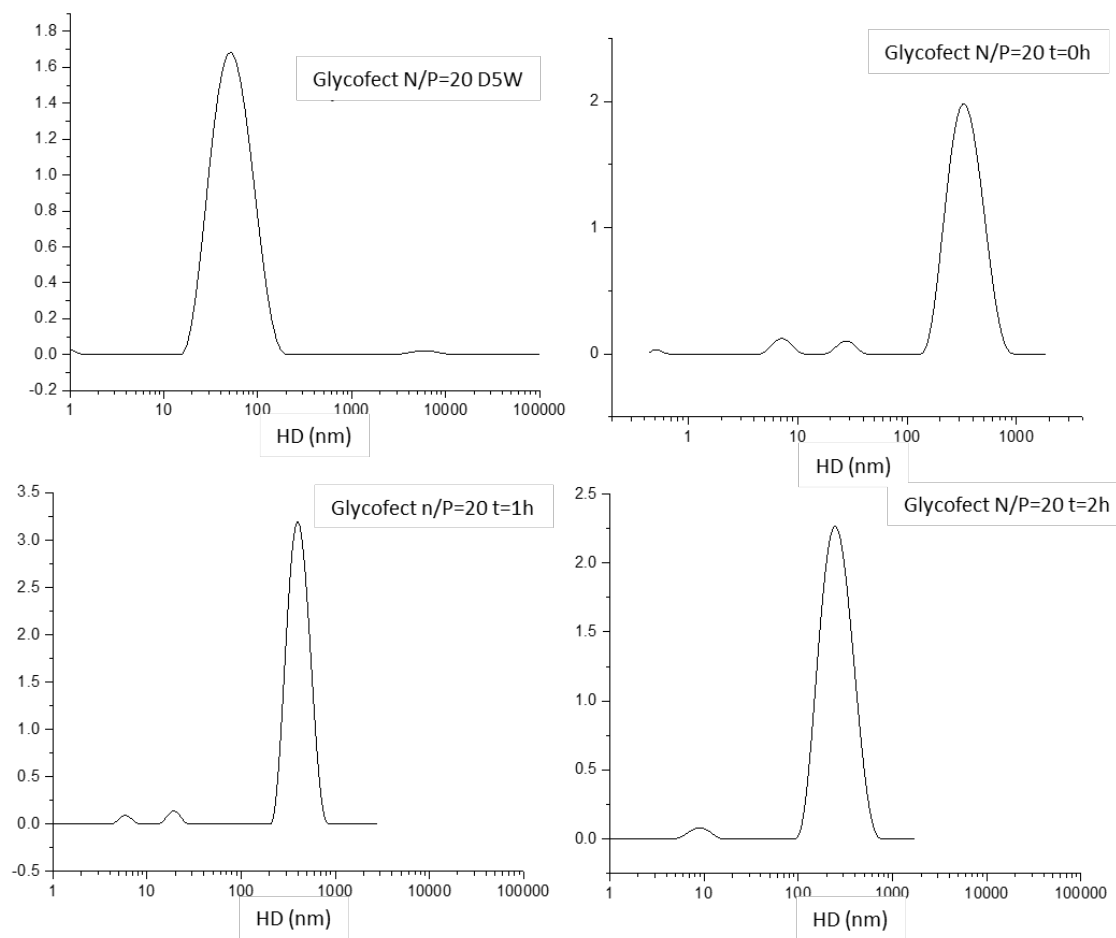

Figure S10. DLS correlation functions of Glycofect N/P $=20$ polyplexes over time transformed by REPES analysis to present the data as a smoothed histogram. Timepoints taken after addition of FBS solution. The $\mathrm{x}$-axis is hydrodynamic diameter (HD) in $\mathrm{nm}$, and the $\mathrm{y}$-axis is unitless intensity. 

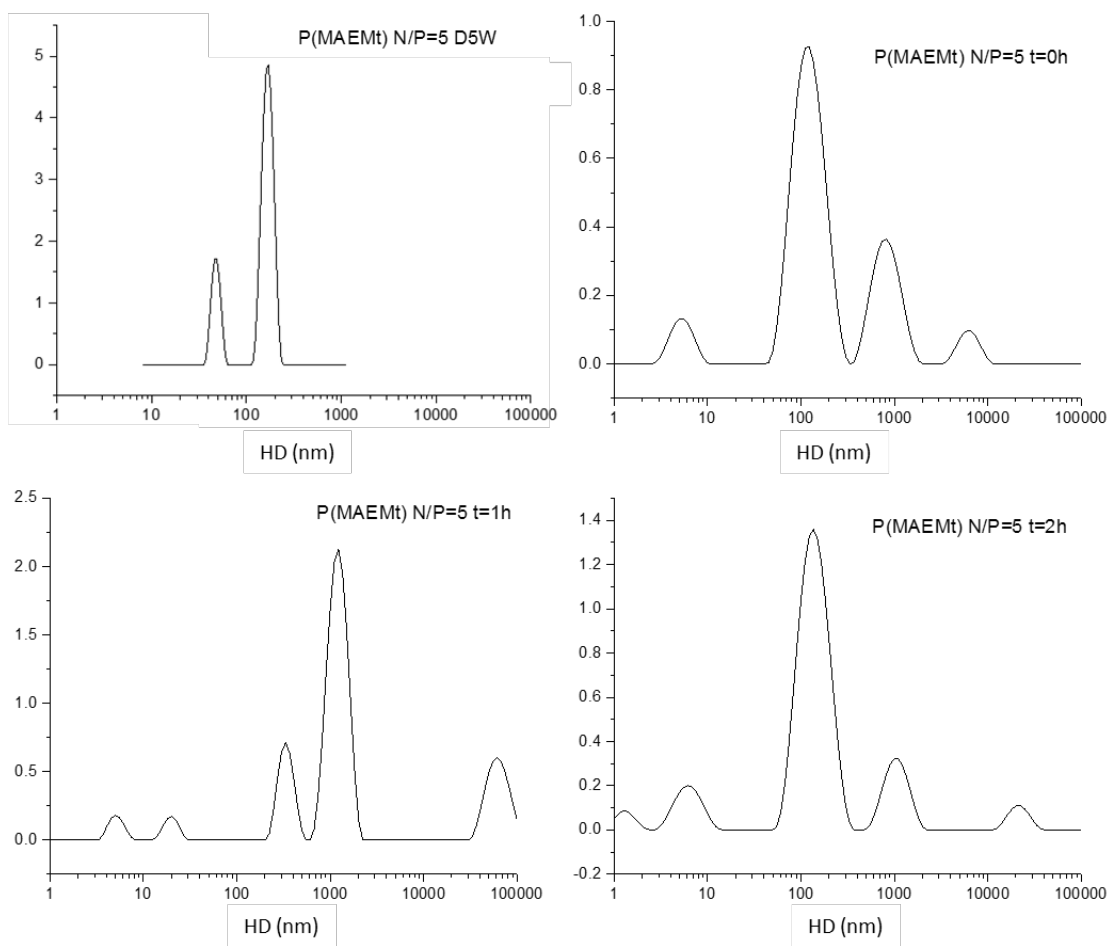

Figure S11. DLS correlation functions of $\mathrm{P}(\mathrm{MAEMt}) \mathrm{N} / \mathrm{P}=5$ polyplexes over time transformed by REPES analysis to present the data as a smoothed histogram. Timepoints taken after addition of FBS solution. The $\mathrm{x}$-axis is the hydrodynamic diameter (HD) in $\mathrm{nm}$, and the $\mathrm{y}$-axis is unitless intensity. 

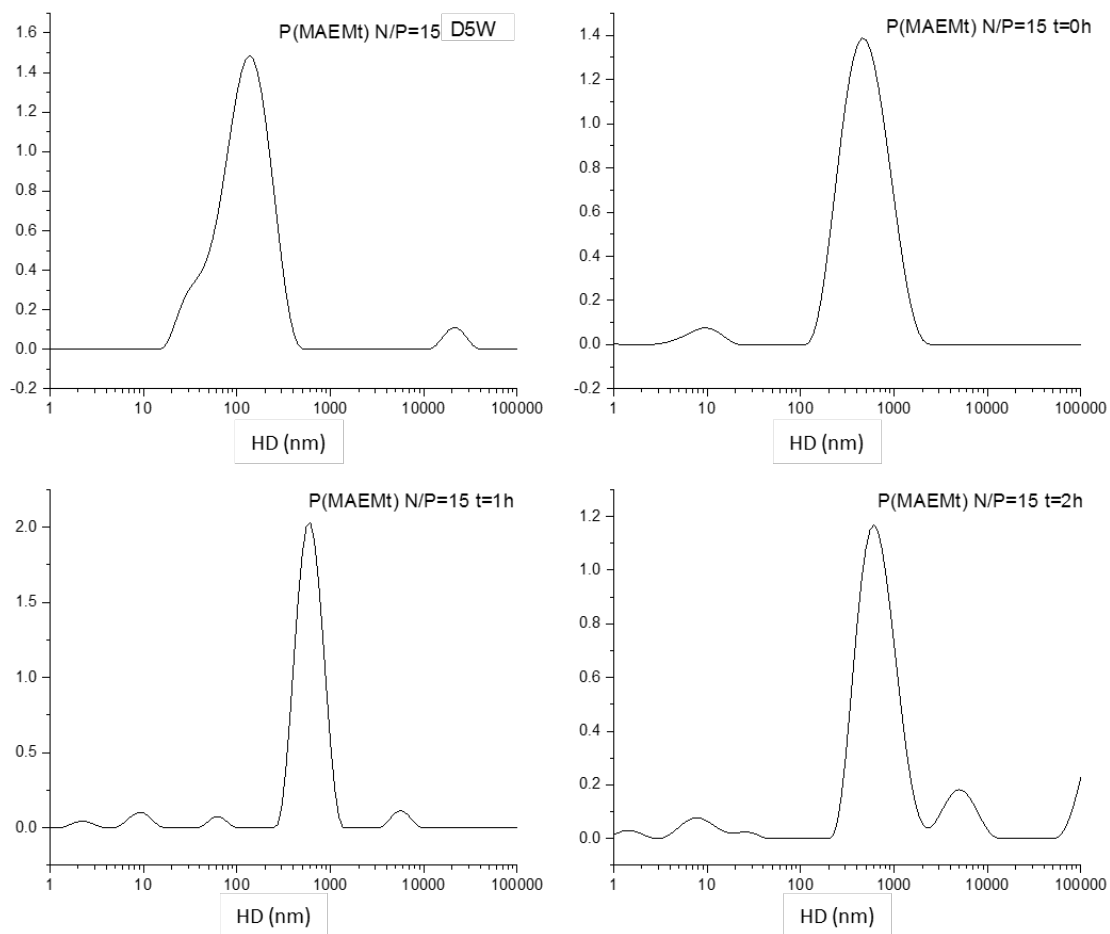

Figure S12. DLS correlation functions of $\mathrm{P}(\mathrm{MAEMt}) \mathrm{N} / \mathrm{P}=15$ polyplexes over time transformed by REPES analysis to present the data as a smoothed histogram. Timepoints taken after addition of FBS solution. The $\mathrm{x}$-axis is the hydrodynamic diameter (HD) in $\mathrm{nm}$, and the $\mathrm{y}$-axis is unitless intensity. 

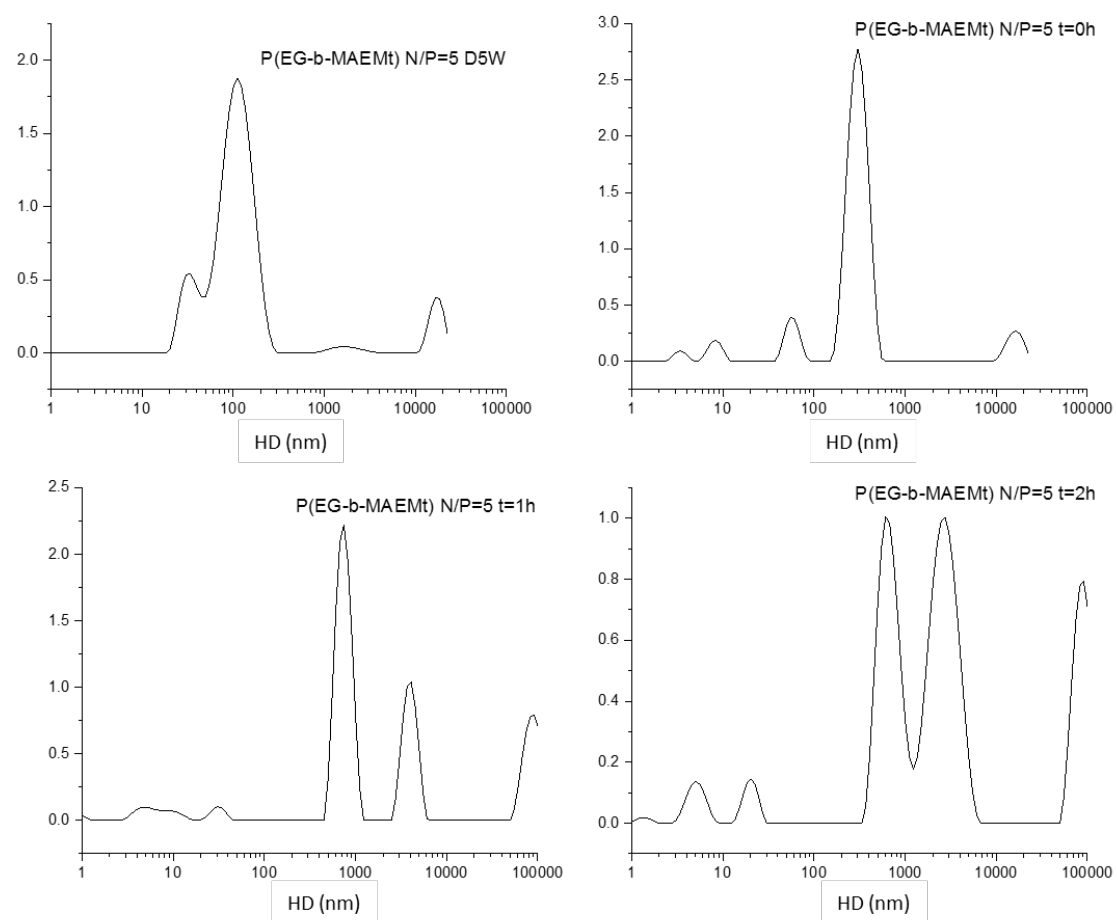

Figure S13. DLS correlation functions of $\mathrm{P}(\mathrm{EG}-b$-MAEMt $) \mathrm{N} / \mathrm{P}=5$ polyplexes over time transformed by REPES analysis to present the data as a smoothed histogram. Timepoints taken after addition of FBS solution. The $\mathrm{x}$-axis is hydrodynamic diameter (HD) in $\mathrm{nm}$, and the $\mathrm{y}$-axis is unitless intensity. 

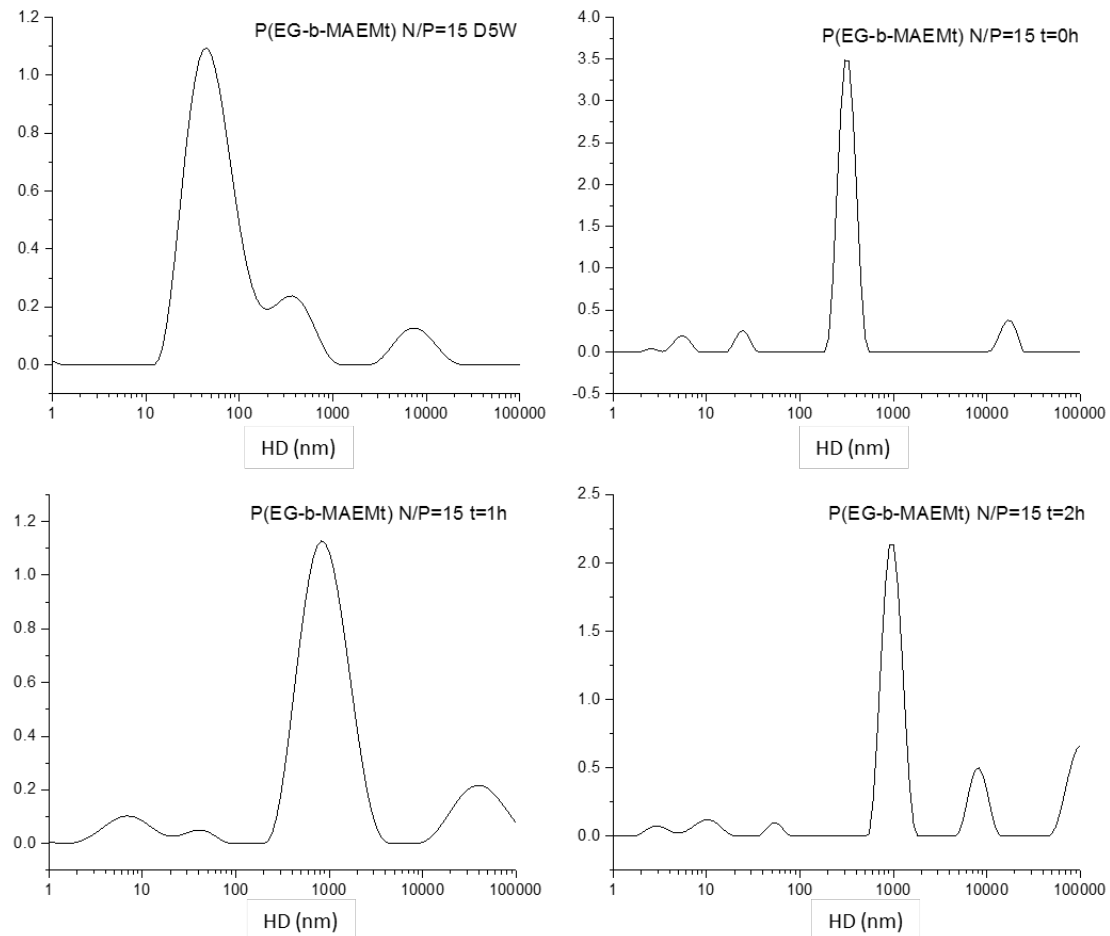

Figure S14. DLS correlation functions of $\mathrm{P}(\mathrm{EG}-b$-MAEMt $) \mathrm{N} / \mathrm{P}=15$ polyplexes over time transformed by REPES analysis to present the data as a smoothed histogram. Timepoints taken after addition of FBS solution. The x-axis is the hydrodynamic diameter (HD) in nm, and the y-axis is unitless intensity. 

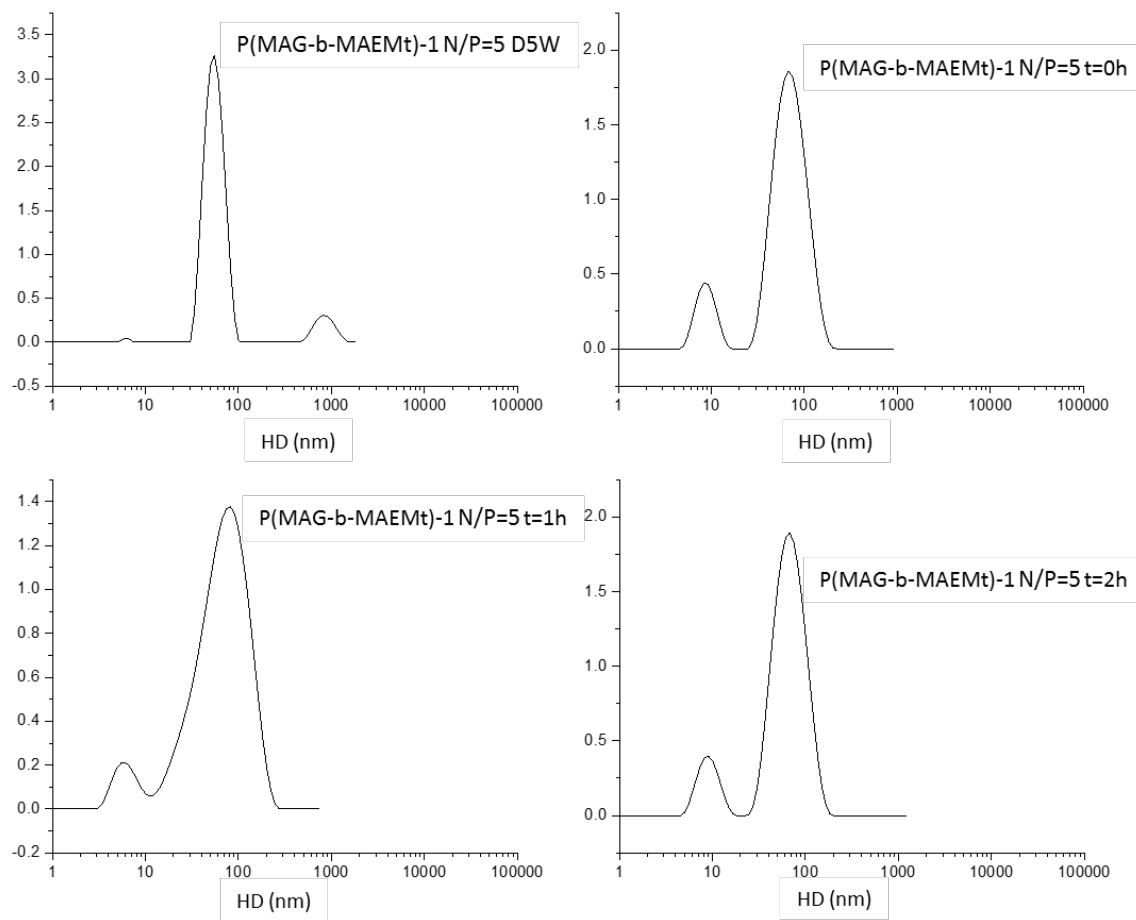

Figure S15. DLS correlation functions of $\mathrm{P}(\mathrm{MAG}-b$-MAEMt)- $1 \mathrm{~N} / \mathrm{P}=5$ polyplexes over time transformed by REPES analysis to present the data as a smoothed histogram. Timepoints taken after addition of FBS solution. The x-axis is the hydrodynamic diameter (HD) in nm, and the y-axis is unitless intensity. 

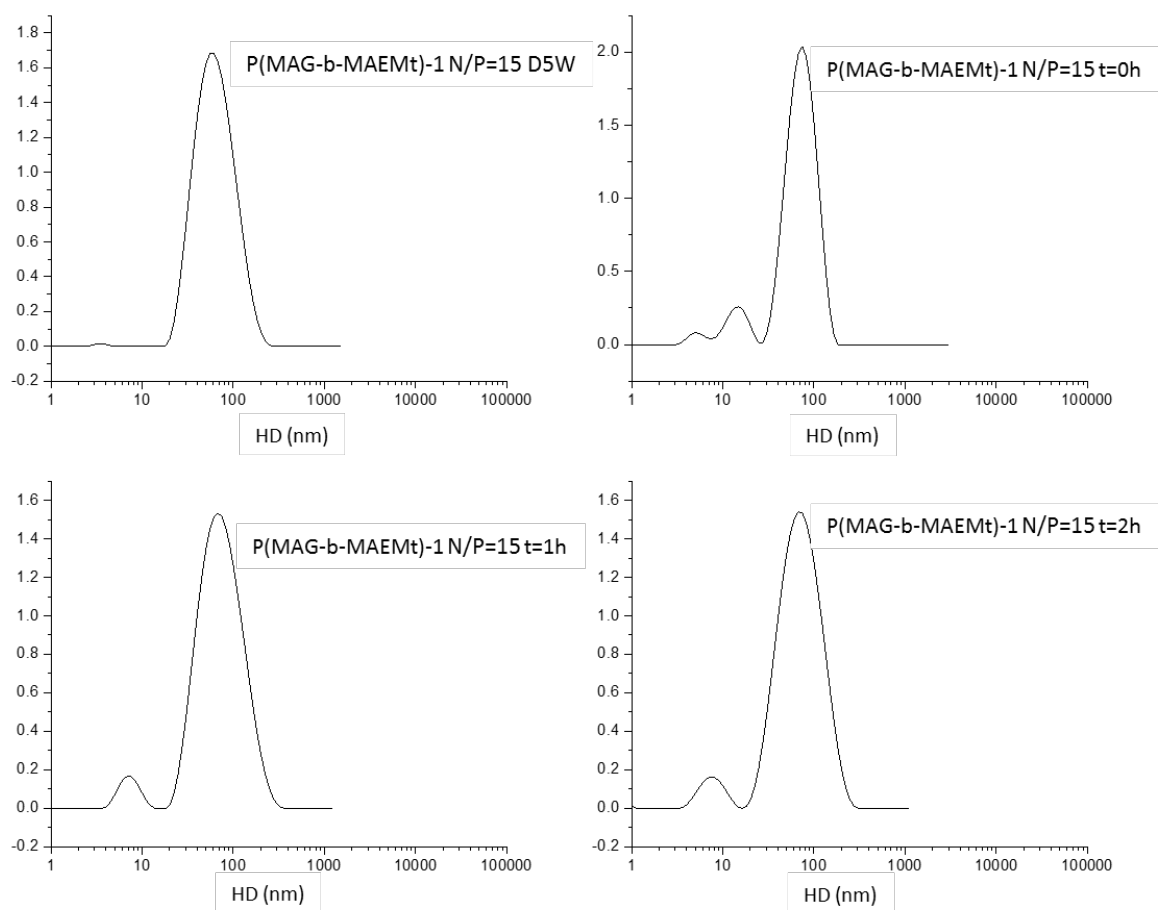

Figure S16. DLS correlation functions of $\mathrm{P}(\mathrm{MAG}-b-\mathrm{MAEMt})-1 \mathrm{~N} / \mathrm{P}=15$ polyplexes over time transformed by REPES analysis to present the data as a smoothed histogram. Timepoints taken after addition of FBS solution. The $\mathrm{x}$-axis is the hydrodynamic diameter (HD) in $\mathrm{nm}$, and the $\mathrm{y}$-axis is unitless intensity. 

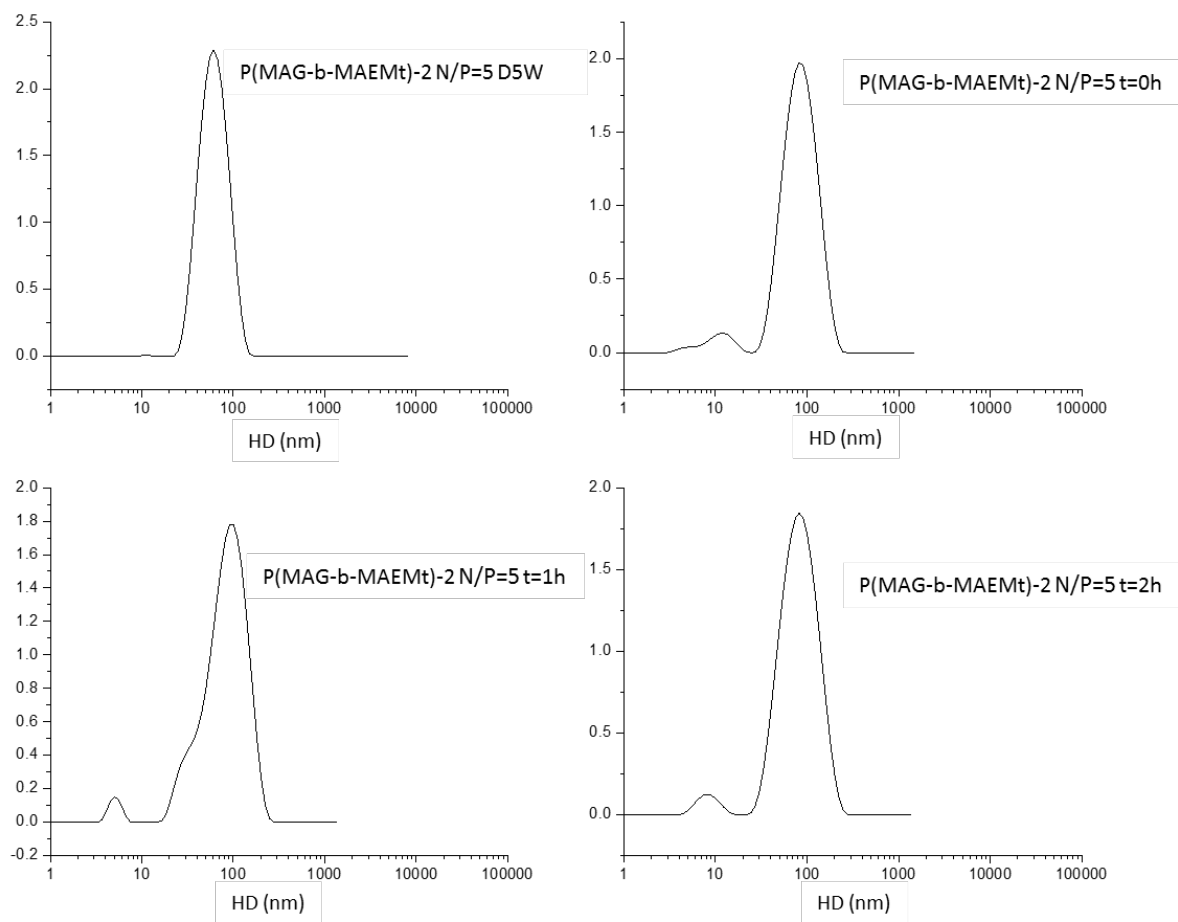

Figure S17. DLS correlation functions of $\mathrm{P}(\mathrm{MAG}-b-\mathrm{MAEMt})-2 \mathrm{~N} / \mathrm{P}=5$ polyplexes over time transformed by REPES analysis to present the data as a smoothed histogram. Timepoints taken after addition of FBS solution. The $\mathrm{x}$-axis is the hydrodynamic diameter (HD) in nm, and the $y$-axis is unitless intensity. 

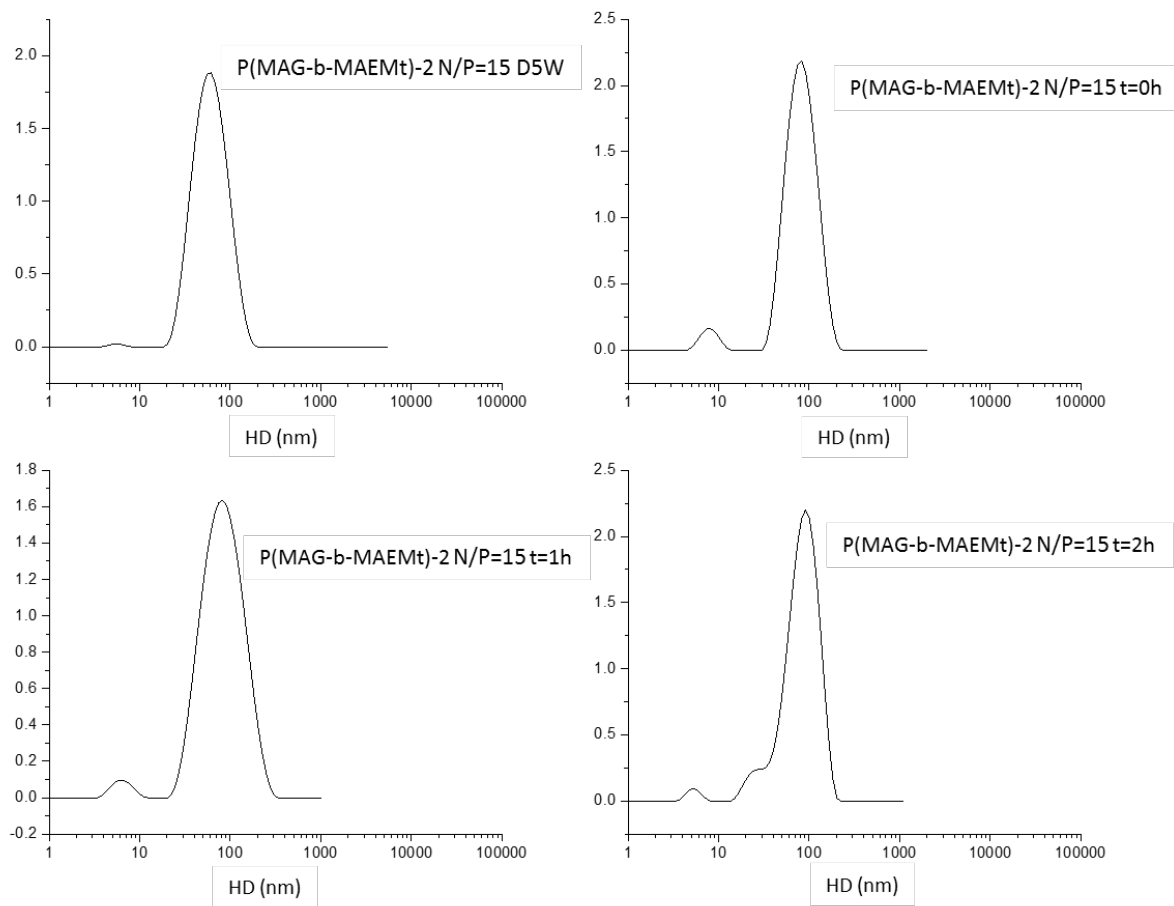

Figure S18. DLS correlation functions of $\mathrm{P}(\mathrm{MAG}-b$-MAEMT)-2 N/P $=15$ polyplexes over time transformed by REPES analysis to present the data as a smoothed histogram. Timepoints taken after addition of FBS solution. The $\mathrm{x}$-axis is the hydrodynamic diameter (HD) in nm, and the y-axis is unitless intensity. 

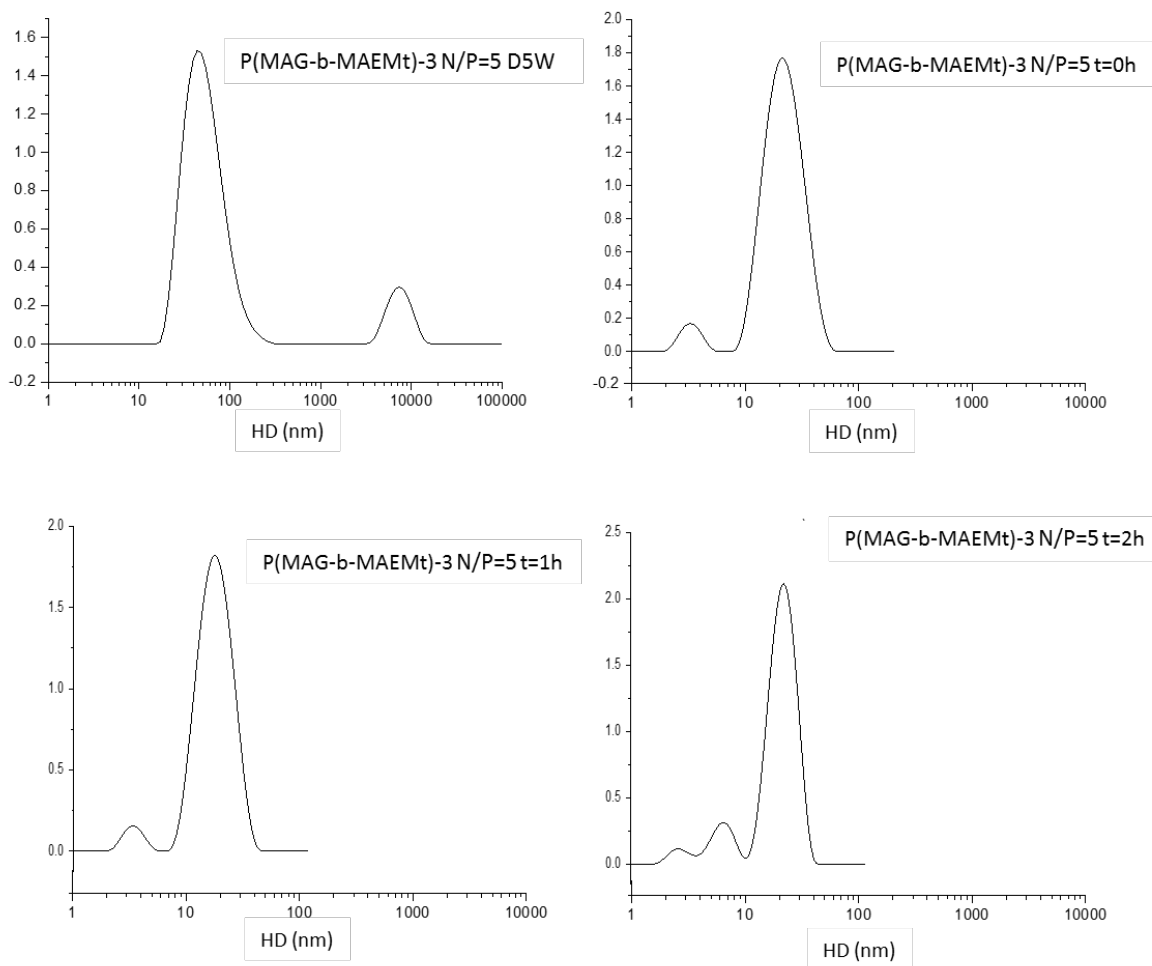

Figure S19. DLS correlation functions of $\mathrm{P}(\mathrm{MAG}-b$-MAEMT)-3 N/P $=5$ polyplexes over time transformed by REPES analysis to present the data as a smoothed histogram. Timepoints taken after addition of FBS solution. The $\mathrm{x}$-axis is the hydrodynamic diameter (HD) in nm, and the $\mathrm{y}$-axis is unitless intensity. 

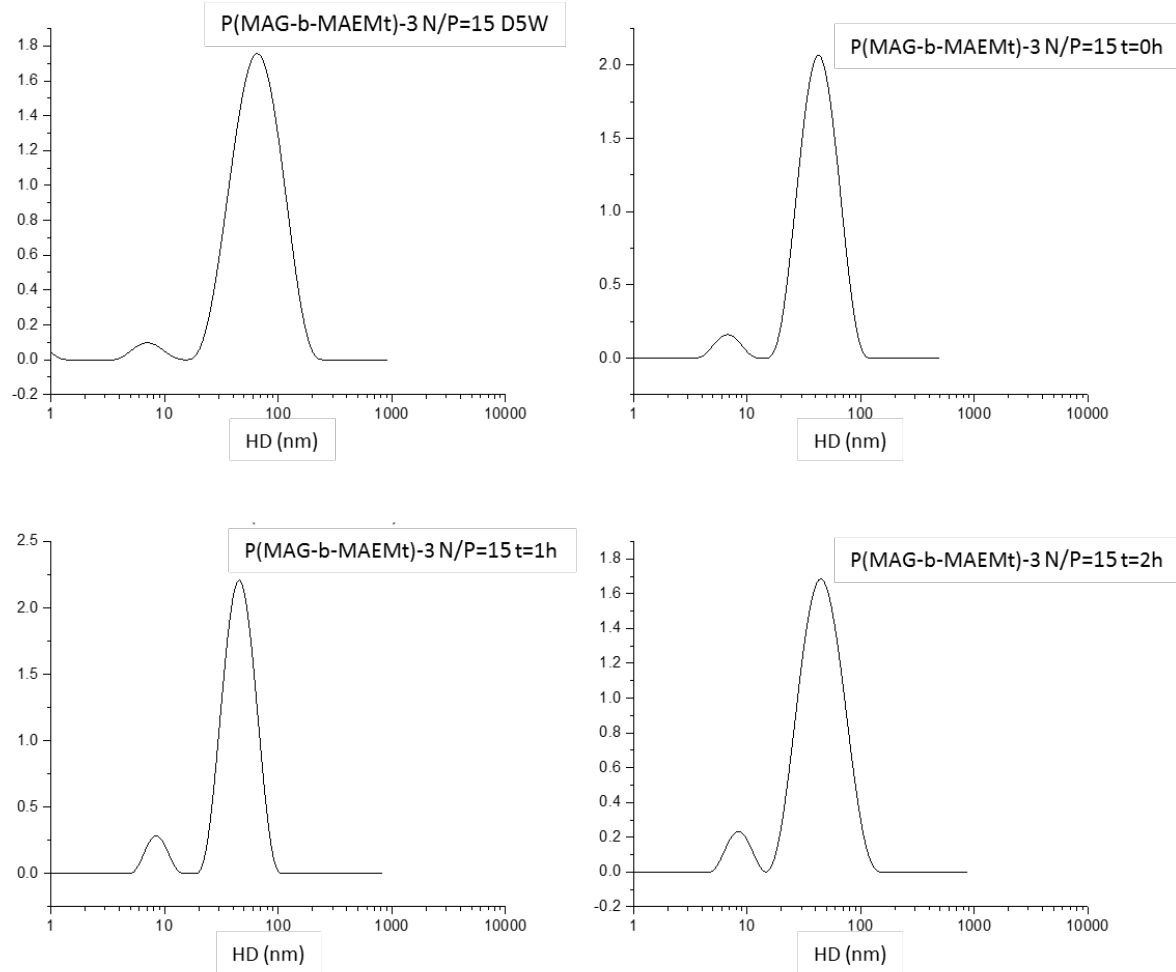

Figure S20. DLS correlation functions of P(MAG- $b$-MAEMt)-3 N/P $=15$ polyplexes over time transformed by REPES analysis to present the data as a smoothed histogram. Timepoints taken after addition of FBS solution. The $\mathrm{x}$-axis is the hydrodynamic diameter (HD) in nm, and the $\mathrm{y}$-axis is unitless intensity.

\section{RBC Morphology Study}

DIC microscopy images were captured to assess any changes to RBC morphology after exposure to polyplexes. No significant morphology alterations were visible, and representative images are shown below in Figure S21. 

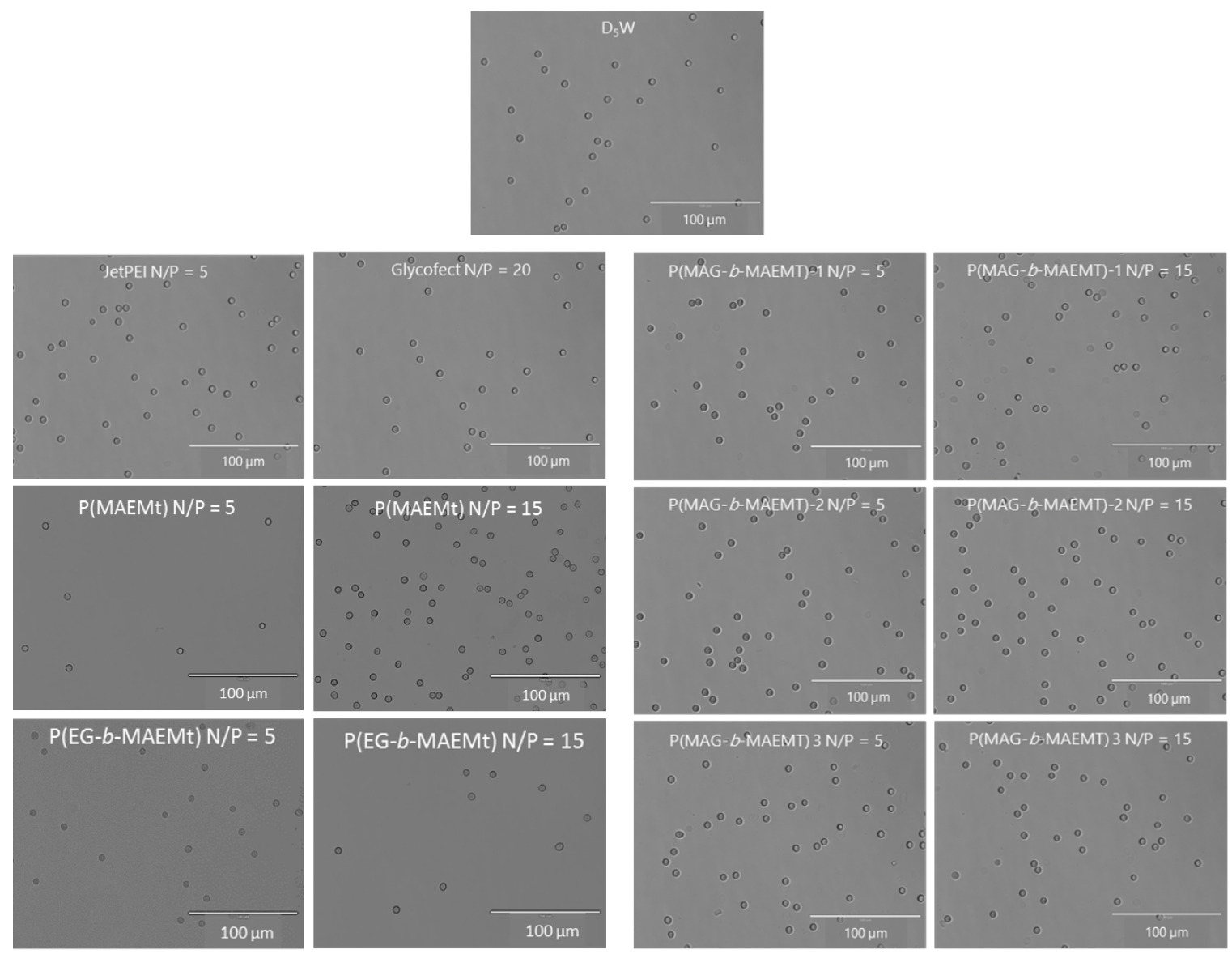

Figure S21. Representative DIC microscopy images at 20x magnification.

\section{Coagulation Studies}

The addition of $\mathrm{P}(\mathrm{MAG}-b$-MAEMt) polyplexes at $\mathrm{N} / \mathrm{P}=15$ increased coagulation time when tested in an aPTT assay. To determine if this was due to the polyplexes blocking contact activation by complexing with reagent, we conducted a mixing study by adding more of either plasma ( $50 \%$ by volume or $150 \mu \mathrm{L})$ or reagent $(200 \mu \mathrm{L})$ and tested aPTT again according to the protocol described in the main manuscript. ${ }^{6,7}$ Adding more reagent decreased aPTT significantly in all cases, but only adding more plasma completely restored coagulation time to normal. This indicates it was the binding up of coagulation factors by polyplexes that most contributed to delaying coagulation. 


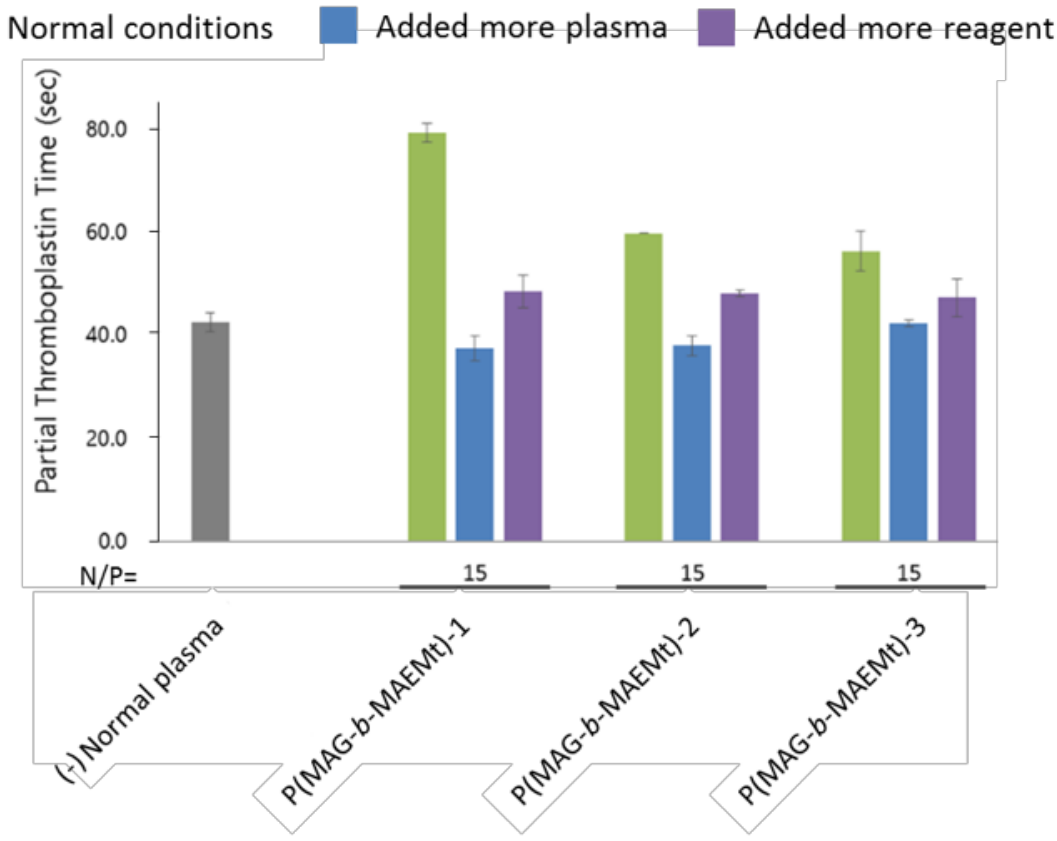

Figure S22. Coagulation times in seconds for human platelet poor plasma (PPP) only samples compared to PPP samples incubated with polyplexes at N/P $=15$ for $1 \mathrm{~h}$. The green bars show results when testing with normal aPTT assay conditions. The blue bars are the results when $50 \%$ by volume PPP (150 additional $\mu \mathrm{L})$ was added to the test tube during the assay, and the purple bars are the coagulation times when twice as much reagent was used.

\section{Biodistribution Studies}

Polymer Biodistribution. Polyplex solutions $(200 \mu \mathrm{L})$ were prepared in $\mathrm{D}_{5} \mathrm{~W}$ at $\mathrm{N} / \mathrm{P}$ ratios of 5 and 15, allowed to complex for $1 \mathrm{~h}$ at room temperature, and injected into mice via the tail vein. Mice were euthanized by $\mathrm{CO}_{2}$ inhalation $1 \mathrm{~h}$ post-injection. Blood was collected by cardiac puncture and then the circulatory system was perfused with at least $20 \mathrm{~mL}$ of saline. We then collected the heart, lungs, kidneys, spleen, liver, and brain and imaged them using Living Image software (PerkinElmer Inc., Waltham, MA), with an excitation wavelength of $710 \mathrm{~nm}$, an exposure time of $3 \mathrm{sec}$, and an absorbance wavelength of $780 \mathrm{~nm}$. The organ images were quantified by hand drawing a region of interest (ROI) around the edge of each organ and counting the radiance efficiency $\left(\left(\right.\right.$ photons $\left.\left./ \mathrm{sec} / \mathrm{cm}^{2} / \mathrm{sr}\right) /\left(\mu \mathrm{W} / \mathrm{cm}^{2}\right)\right)$ to normalize all measurements into directly comparable values shown in Figure 6A (main manuscript) and Figure S18A-D. The tissues were then flash frozen in liquid $\mathrm{N}_{2}$ and stored at $-80^{\circ} \mathrm{C}$. Frozen tissue was bead milled by a BulletBlender ${ }^{\mathrm{TM}}$. Next, $100 \mathrm{mg}$ of each organ 
was diluted in $700 \mu \mathrm{L}$ of Qiagen lysing buffer and $15 \mu \mathrm{L}$ proteinase $\mathrm{K}(20 \mu \mathrm{g} / \mu \mathrm{L})$ and incubated overnight at $55^{\circ} \mathrm{C}$ on an elliptical shaker. Next, a standard phenol chloroform extraction was performed to extract all DNA from the sample for quantitative polymerase chain reaction (qPCR) analysis by the University of Minnesota Genomics Core. DNA was precipitated in cold ethanol and resuspended in 0.1x Tris EDTA. DNA concentration and purity were assessed using a NanoDrop instrument (Thermo Fisher Scientific). 


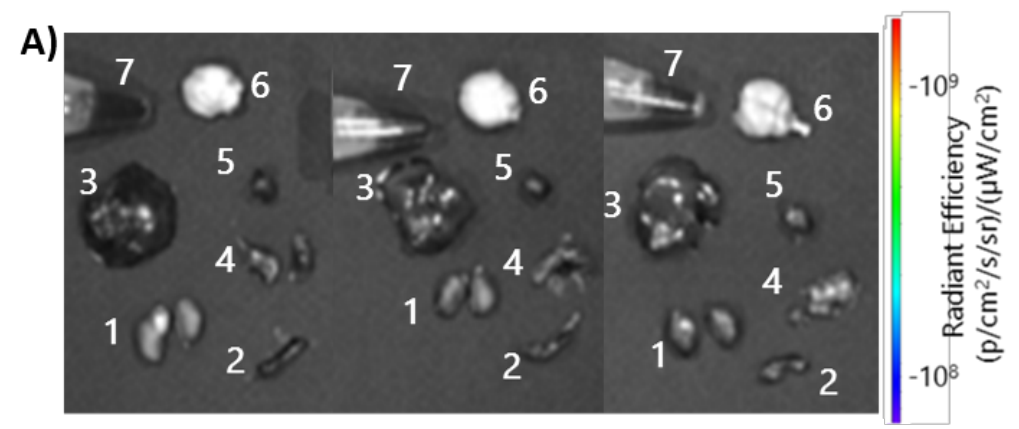

B)

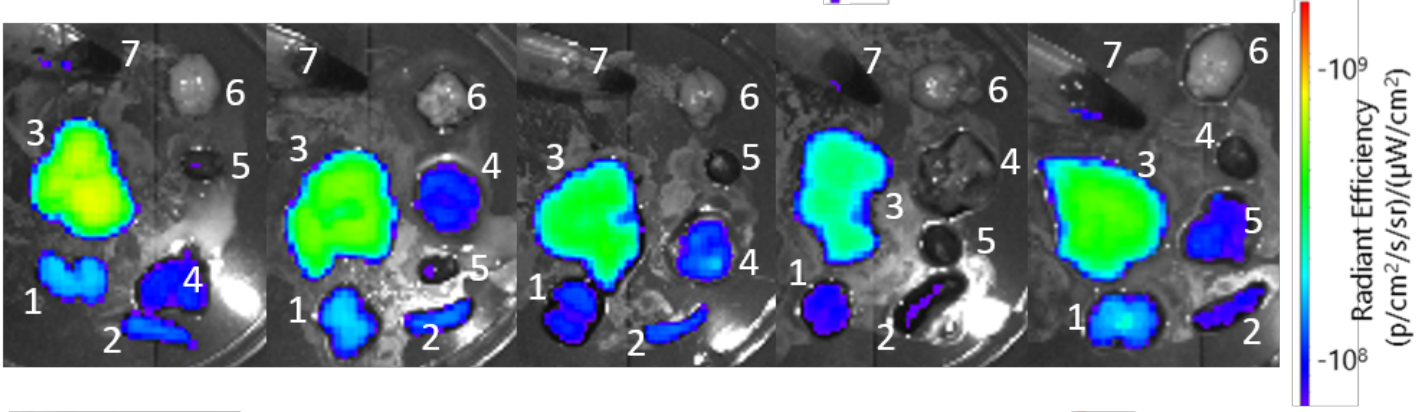

C)

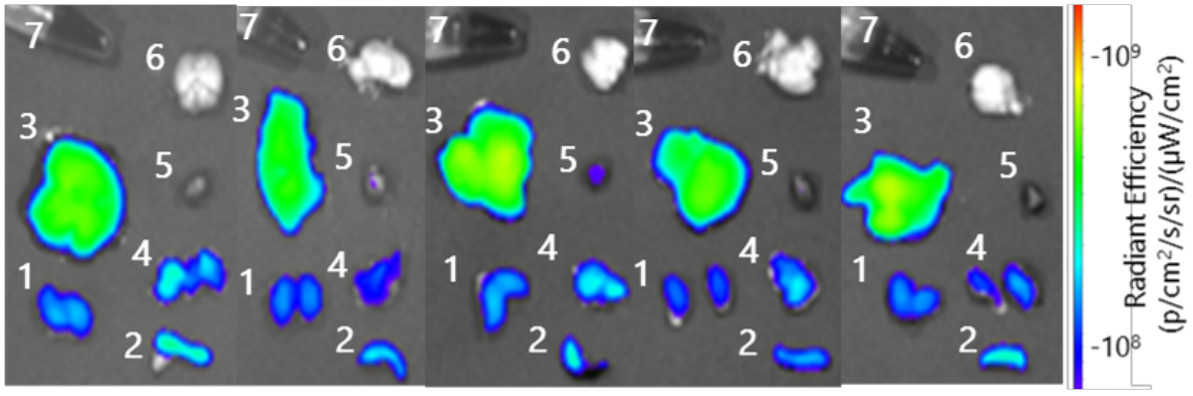

D)

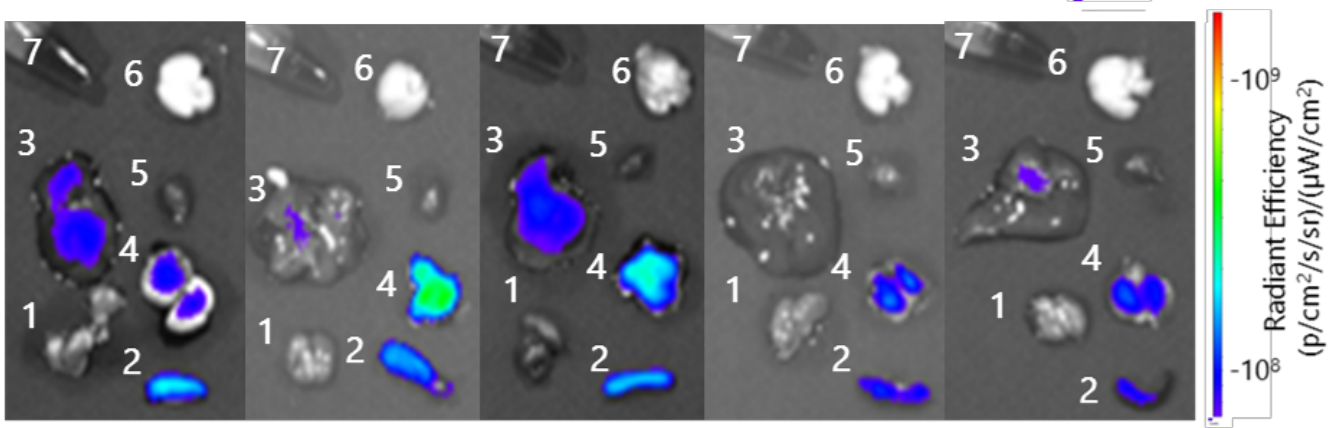
1) Kidneys
2) Spleen
3) Liver
4) Lungs
5) Heart
6) Brain
7) Blood

Figure S23. Fluorescent organ images after $\mathrm{D}_{5} \mathrm{~W}$ or polyplex injection. (A) $\mathrm{D}_{5} \mathrm{~W}$ only. (B) $\mathrm{P}(\mathrm{EG}-b-$ MAEMt)-Cy7 N/P = 5. (C) P(MAG- $b$-MAEMt)-2-Cy7 N/P = 5. (D) P(MAG- $b$-MAEMt)-2-Cy7 N/P $=15$.

pDNA Biodistribution. $500 \mathrm{ng}(100 \mathrm{ng} / \mu \mathrm{L})$ of extracted DNA was used for qPCR analysis with TaqMan primers. A TaqMan Gene Expression Master Mix Custom Plus TaqMan Assay (Assay ID AJ6RNJ4, Life Technologies - Thermo Fisher Scientific, Carlsbad, CA) was used. On a per sample 
basis each assay consisted of $10 \mu \mathrm{L}$ of $2 \times$ reaction mix, $1 \mu \mathrm{L}$ TaqMan assay solution (part of Taqman kit listed above), and $7 \mu \mathrm{L}$ RT-PCR Grade water (Ambion, Life Technologies - Thermo Fisher, Inc., Carlsbad, CA). All reagents were kept on ice as the DNA was added. A pT2/CAL standard curve was serially diluted into C57BL/6 mouse genomic DNA, and samples were run on impulse setting at $95{ }^{\circ} \mathrm{C}$ for $10 \mathrm{~min}$. Each sample was then cycled 40 times at $90{ }^{\circ} \mathrm{C}$ for $15 \mathrm{~s}$ followed by $60{ }^{\circ} \mathrm{C}$ for $1 \mathrm{~min}$.

Outlier analysis on all organ qPCR data was performed using Grubb's test via GraphPad's online software (https://graphpad.com/quickcalcs/grubbs1/; accessed April 10, 2017). The organ samples that were removed from the qPCR data prior to plotting in Figure 5C are as follows: mouse 1's kidney dosed with $\mathrm{D}_{5} \mathrm{~W}$; mouse 3's heart dosed with $\mathrm{D}_{5} \mathrm{~W}$, mouse 45 's spleen dosed with $\mathrm{P}(\mathrm{EG}-b$ MAEMt) N/P $=5$, mouse 45's liver dosed with $\mathrm{P}$ (EG- $b$-MAEMt) N/P $=5$, and mouse 25's kidney dosed with $\mathrm{P}(\mathrm{MAG}-b$-MAEMt)-2 N/P $=5$.

\section{REFERENCES}

(1) Li, H.; Cortez, M. A.; Phillips, H. R.; Wu, Y.; Reineke, T. M. ACS Macro Lett. 2013, 2 (3).

(2) Sprouse, D.; Reineke, T. M. Biomacromolecules 2014, 15 (7), 2616-2628.

(3) Kali, G.; Georgiou, T. K.; Iván, B.; Patrickios, C. S. J. Polym. Sci., Part A: Polym. Chem. 2009, 47 (17), 4289-4301.

(4) Xu, X.; Smith, A. E.; Kirkland, S. E.; McCormick, C. L. Macromolecules 2008, 41 (22), 84298435.

(5) Smith, A. E.; Sizovs, A.; Grandinetti, G.; Xue, L.; Reineke, T. M. Biomacromolecules 2011, 12 (8), 3015.

(6) Making Sense of Mixing Studies. http://kingbiomed.com/blog/making-sense-of-mixing-studies (accessed April 4, 2016).

(7) Deo, A. Mixing Studies. https://allaboutblood.com/2013/10/08/mixing-studies (accessed March 29, 2017). 